\title{
Psicologia e Arquitetura: em busca do locus interdisciplinar
}

Gleice Azambuja Elali

Universidade Federal do Rio Grande do Norte

Resumo:

Partindo do reconhecimento da inevitável interdisciplinaridade no estudo da relação pessoa-ambiente, o artigo discute a Psicologia Ambiental enquanto locus privilegiado na interseção entre Psicologia e Arquitetura, com especial ênfase para a interrelação ambiente construído - comportamento humano. Definindo a escolha dos métodos de pesquisa como fator crucial a esta posição interdisciplinar, o texto aponta os principais métodos atualmente utilizados, facilidades de aplicação e vantagens/desvantagens dos mesmos, defendendo a propriedade do uso de multimétodos na realização de trabalhos na área.

Palavras Chave: Psicologia Ambiental; Relação Comportamento Ambiente Construído; Abordagem Multimétodos.
Key-words: Environmenta Psychology, Buil Environment

Evaluation, Multi-method approach.

\begin{abstract}
:
Psychology and Architecture: looking for the interdisciplinary locus. Acknowledging interdisciplinarity as an inevitable condition for the study of person-environment relationship, the article discusses Environmental Psychology as locus of intersection between Psychology and Architecture, converging upon the interrelationship human behavior - built environment. Considering that the choice of research methods is an essential element to such an approach, the text defines the main methods and techniques used in this area, their application and advantages/disadvantages, emphasizing a multimethod strategy.
\end{abstract}




\begin{abstract}
O homem e suas extensões constituem um sistema inter-relacionado. É um erro agir como se os homens fossem uma coisa e sua casa, suas cidades, sua tecnologia, ou sua língua, fossem algo diferente. Devido à inter-relação entre o homem e suas extensões é conveniente prestarmos uma atenção bem maior ao tipo de extensões que criamos (...). Como as extensões são inanimadas, é preciso alimentá-las com feedback (pesquisa), para sabermos o que está acontecendo, em particular no caso das extensões modeladoras ou substitutivas do meio ambiente natural. (E. Hall, 1966, pp. 166-167)
\end{abstract}

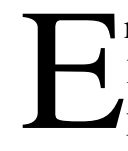

mbora tenha sido escrito há mais de 30 anos, o texto de Edward Hall aponta, desconcertantemente, uma área de trabalho ainda pouco explorada. Desconcertantemente, porque apesar da nossa capacidade para criar/modelar espaços e, sobretudo, embora a humanidade viva essencialmente em ambientes edificados (a maior parte da população mundial habita em cidades), pouco tem sido construído no sentido de ampliar o conhecimento da interface entre ambiente e comportamento humanos.

De fato, apesar da evidente necessidade de nos tornarmos atentos à inter-relação entre o homem e as extensões que cria para si, continuamos a estudar isoladamente cada fator envolvido nesta complexa equação. Grande parte do problema diz respeito à própria indefinição sobre a área, ou áreas, de conhecimento a que pertence o estudo desta relação, com possíveis vertentes em Psicologia, Sociologia, Antropologia, Arquitetura, Urbanismo, Geografia, entre outras. No entanto, a principal causa desta dificuldade parece relacionar-se à relativa estagnação do conhecimento dentro de cada setor, fruto da intensa compartimentalização da ciência em busca da super-especialização: a Medicina dedica-se ao estudo das condições de saúde do corpo; a Psicologia analisa o comportamento humano; a Sociologia aborda a relação entre os indivíduos; a Arquitetura projeta os edifícios que os abrigam; o Urbanismo dedica-se à planificação das cidades... 
Paradoxalmente, embora seja óbvia a complementaridade entre estes e outros campos de trabalho, envolvendo faces diferentes de uma mesma problemática, as informações geradas em cada "grupo de estudos" pouco se expande além de seus próprios pares, dificultando a formação de uma massa crítica interdisciplinar que alimente um processo investigativo mais amplo. Felizmente, o gradual surgimento de trabalhos interdisciplinares tem induzido mudanças paradigmáticas no enfrentamento desta temática, com ênfase para a necessidade do reagrupamento das disciplinas e o surgimento de novas formas de atuação nas diferentes profissões.

\section{Uma questão de complementariedade}

Em Psicologia e Arquitetura, duas das áreas mais proximamente ligadas ao estudo da relação pessoa-ambiente, este quadro não é diferente. Gradualmente a Psicologia ampliou sua área de atuação do indivíduo para o social e o ambiental, "redefinindo" e complementando seu objeto de estudo de modo a abarcar as interações ambientecomportamento, e contribuindo para um conhecimento mais amplo da realidade através de um enfoque ecológica e humanamente consistente. Em Arquitetura, por sua vez, aos poucos observa-se o deslocamento da ênfase na análise de aspectos estéticos/construtivos/ funcionais do edifício para a preocupação com a percepção/satisfação dos usuários e com as implicações das intervenções em termos de paisagem, propiciando a elaboração de propostas mais centradas no indivíduo e/ou no social e nas implicações ecológicas das interferências realizadas.

Tais constatações denotam uma gradativa aproximação e valoração entre tais campos, em cujo "espaço de complementação" o estudo do ambiente impõe-se enquanto locus extremamente privilegiado para interação e geração de conhecimento. Assim, embora muitas vezes a Arquitetura seja encarada como profissão-cliente da Psicologia (à qual recorreria para aprofundar a análise de aspectos ligados à percepção e comportamento ambientais), o rebatimento de tais estudos não é imediato ou simples, de maneira que somente a parceria entre ambas, na realização de trabalhos conjuntos que contemplem as suas especificidades, pode vir a possibilitar a real ampliação dos conhecimentos. 
Este esforço passa necessariamente pelo enfrentamento das dificuldades no contato entre as áreas, principalmente em função das diferenças de "tempo" e "linguagem" implícitos. Enquanto para os psicólogos, por exemplo, a preocupação reside no indivíduo (ou grupo) e nos processos de sua interação, cuja compreensão implica longo período de envolvimento, os problemas que se apresentam aos arquitetos exigem respostas quase imediatas, em função de prazos exíguos criados por exigências práticas ou institucionais. Por outro lado, no que se refere às formas de comunicação utilizadas, enquanto arquitetos recorrem eminentemente à linguagem gráfica essencial ao processo projetual, os psicólogos analisam aspectos subjetivos da vivência individual, envolvendo sobretudo elementos verbais e a expressão corporal, dificilmente decodificáveis pelos primeiros em termos de suas atividades profissionais.

Ora, uma vez que nem a Psicologia tradicional nem a Arquitetura consegue abarcar totalmente a relação pessoa-ambiente, torna-se inevitável a procura de um espaço comum entre ambas. Alimentada pelas duas áreas, porém relativamente independente destas, a Psicologia Ambiental habilita-se a ser este espaço, constituindo-se locus onde a soma entre o conhecimento psicológico e o arquitetônico pode alimentar a produção de um ambiente mais humanizado e ecologicamente coerente. Enquanto campo nitidamente multidisciplinar, centrado no objeto de estudo, e não numa área específica de conhecimento, a Psicologia Ambiental pode desempenhar o papel de "ponte" que, enfatizando e valorizando semelhanças e diferenças entre conhecimentos arquitetônicos e psicológicos, possibilita as necessárias trocas, enriquecendo a ambos através da soma de conceitos, experiências e métodos de trabalho, além de abrir-se à contribuição de áreas afins (como Geografia, Sociologia e Antropologia, entre outras), o que amplia a abrangência e a potencialidade dos estudos a serem realizados.

Enquanto "disciplina em construção", a Psicologia Ambiental tem como um de seus principais objetos de estudo a avaliação do ambiente construído durante o processo de sua ocupação, o que tem contribuido decisivamente para a divulgação da área (Bechtel, 1996; Stokols, 1996; entre outros), apontando para a construção de um corpo teóricometodológico sólido e a formação de bancos de dados enquanto fontes 
de informação essenciais ao avanço da área. A crescente importância do trabalho avaliativo enquanto subsídio a novos projetos, ou face a programas de reforma/manutenção do espaço construído (Ornstein 1992, 1997), representa a conscientização de que pouco contribuiremos socialmente se continuarmos a enfrentar cada problema de modo isolado, esquecendo que o principal objetivo da edificação (ou conjunto edificado) deve ser garantir a qualidade de vida da população. Sob esta ótica, o edifício deixa de ser encarado apenas a partir das suas características físicas (construtivas) e passa a ser avaliado/discutido enquanto espaço "vivencial”, sujeito à ocupação, leitura, reinterpretação e/ou modificação pelos usuários, ou seja, ao estudo de aspectos construtivos e funcionais do espaço construído acrescenta-se a anáise comportamental e social essencial à sua compreensão. Esse processo implica, necessariamente, a análise do uso - enquanto fator que possibilita a transformação de espaços em lugares- e a valorização do ponto de vista do usuário, destinatário final do espaço construído, e portanto imprescindível à compreensão da realidade.

Tal tendência, valorizando especialmente os aspectos perceptuais da relação pessoa-ambiente, é plenamente justificada quando se considera que o contato direto e cotidiano de um usuário com um objeto transforma esse indivíduo em um crítico severo e abalizado daquele produto. De fato, embora o confronto entre pareceres técnicos e opiniões leigas possa parecer difícil, estes podem complementar-se eficazmente, como demonstram os Códigos de Direito do Consumidor, em cujos textos encontra-se implícito o processo de realimentação do ciclo produtivo de qualquer objeto. Certamente as pessoas comuns pouco conhecem sobre a fabricação de brinquedos, por exemplo. No entanto, após algum uso as crianças são capazes de dizer/demonstrar se um determinado produto é adequado ou não às suas brincadeiras; os pais compreendem seu potencial de uso ou sua periculosidade; os professores julgam aspectos pedagógicos de sua adoção em sala de aula; os psicólogos os consideram eficazes ou não no processo terapêutico com pacientes de determinada faixa etária etc. Assim, embora nenhum desses usuários possa ser considerado "especialista" na fabricação de brinquedos, a função uso os habilita a realizar tal análise, sendo suas percepções individuais elementos determinantes na 
avaliação do objeto, o que define cada um desses extratos da população como uma fonte potencial de críticas ao produto, propiciando sua alteração para melhor adequação ao público-alvo (os próprios usuários). Apesar desta prática ser comum ao setor industrial, ainda é (desconcertantemente) embrionária no âmbito da construção dos edifícios que nos abrigam durante toda a vida.

Em face desta argumentação, percepção passa a ser uma palavrachave para a realização de trabalhos que envolvam a avaliação do edifício durante o processo de sua utilização, sendo identificada por Monzéglio (1990) como “...fator de relevância para análise do ambiente em fruição, indicando e dimensionando seus aspectos qualitativos, de categorias tipológicas, incidência e relações, alertando sobre as demandas e anseios de melhoria, tendo em vista a evolução, atualização e as projeções futuras (...), avaliação que procede segundo seu alcance de conhecimento para uso também de seu alcance no saber e na cultura própria.” (p. 33).

Quando averiguada a partir do ponto de vista da Psicologia Ambiental a percepção do ambiente construído pelos usuários permite a discussão das potencialidades do ambiente enquanto base-física, que propicia ou inibe a emissão dos comportamentos. Tal estudo, com forte embasamento no modelo teórico da Psicologia Ecológica de Barker (Barker, 1968) possibilita a identificação, descrição e análise das características ambientais e comportamentais do local estudado, com destaque para o conceito de behavior setting que inter-relaciona diretamente os dois fatores, constituindo importante fonte de informação para atuação no local (Pinheiro, 1986).

De fato, é na complementação entre os métodos utilizados e os enfoques dados à análise (em busca da consolidação do arsenal de técnicas e procedimentos relativos ao estudo e avaliação do ambiente construído) que a interação entre arquitetos e psicólogos pode contribuir efetivamente para a evolução do conhecimento relativo às relações pessoa-ambiente, sobretudo no que diz respeito à abordagem dos problemas a partir do confronto entre os pontos de vista dos diferentes agentes envolvidos na produção e apreensão do espaço. Portanto, considerando a definição da tarefa a partir desta interação entre disciplinas (o que, além do embasamento multidisciplinar, 
pressupõe a busca de respostas que tenham rebatimento nas diferentes áreas envolvidas), a escolha do método de pesquisa constitui-se etapa fundamental para a abordagem das questões relevantes para cada estudo.

\section{Uma questão de método}

De modo abrangente, os métodos de pesquisa podem ser subdivididos em qualitativos e quantitativos, e durante muito tempo discutiuse vantagens e desvantagens de ambos no processo de pesquisa, sendo os primeiros prioritariamente associados à validação das informações e os segundos mais relacionados à definição de sua confiabilidade, possibilitando generalizações (Reis \& Lay, 1995). Gradativamente, no entanto, tal discussão tem dado lugar à utilização de multimétodos (Sommer \& Sommer, 1980), isto é, a adoção simultânea de diferentes fontes e técnicas para coleta de dados, prática que colabora para o enriquecimento da avaliação, aumentando significativamente o leque dos elementos envolvidos no processo analítico. De modo geral, estes trabalhos justificam que os dados provenientes de uma única fonte são passíveis de dúvida, uma vez que a aplicação isolada de um método ou técnica pode gerar lacunas no conhecimento obtido, apontando para resultados que contemplam apenas uma faceta da realidade. Sob este ponto de vista torna-se aconselhável que, para evitar viéses metodológicos, os desvios surgidos a partir de um tipo de coleta de dados sejam contrabalançados por informações originadas em outras formas de pesquisa, minimizando as distorções no resultado final do trabalho (Bechtel, Marans \& Michelson, 1987; Marans \& Spreckelmeyer, 1987). Nestes termos, se a adoção de multimétodos é valorizada dentro de uma mesma área, seu efeito pode ser ampliado caso os métodos e técnicas escolhidos possam contemplar visões diferentes de uma mesma realidade, como as provenientes de diferentes campos de conhecimento (no caso, Psicologia e Arquitetura), o que tornaria o leque de informações ainda mais promissor.

Nos trabalhos de avaliação do ambiente edificado os principais métodos atualmente utilizados para a coleta de informações são observações, entrevistas, questionários e medições (levantamentos físicos), os dois primeiros associando-se especialmente a aspectos qua- 
litativos, enquanto os segundos mais relacionados a definições quantitativas. Para efeito didático alguns destes métodos e técnicas serão descritos sucintamente, não visando a sua definição precisa mas, principalmente, buscando ilustrar diferenças entre estes e vantagens/desvantagens no seu uso.

No que se refere ao método de observação, entre as principais técnicas podem-se citar a análise de traços de comportamento e o mapeamento comportamental. A análise de traços de comportamento (Sommer \& Sommer, 1980) consiste na busca de evidências físicas do comportamento dos usuários (desgaste de materiais, lixo, grafitagem etc). Pela facilidade e rapidez na apreensão de dados, a técnica mostrase bastante eficiente em termos qualitativos, apesar de não permitir uma leitura quantitativa imediata das informações, e exigir treinamento dos pesquisadores participantes para o reconhecimento das evidências ambientais do efetivo uso no local. Já o mapeamento comportamental (Ittelson, Proshansky, Rivlin \& Winkel, 1974; Sommer \& Sommer, 1980) relaciona diretamente ambiente e comportamento em função do tempo. Suas principais modalidades dizem respeito ao foco de atenção do observador, podendo definir-se como centradas-no-lugar ou centradas-na-pessoa. Sistematizando informações normalmente apreendidas de modo intuitivo, o mapeamento possibilita a utilização de dados concretos (e portanto menos contestáveis e mais condizentes com a realidade), embora implique a demanda de um tempo considerável, intenso treinamento da equipe, e um considerável trabalho na organização dos dados para análise, fatores que dificultam a sua realização. Sua principal vantagem diz respeito à própria linguagem dos mapas, facilmente decodificável por leigos e por profissionais ligados ao design, facilitando o intercâmbio de dados provenientes das ciências sociais e elementos eminentemente físicos da área, fundamental àqueles que buscam atuar diretamente na análise e reestruturação do espaço.

Também os mapas cognitivos ou mentais (Lynch, 1970; Cullen, 1974, entre outros) dão especial ênfase à linguagem gráfica, diferindo da técnica anterior no que se refere ao tipo de ação do respondente que, desta feita, assume papel mais ativo, sendo levado a desenhar/ 
diagramar/descrever ambientes, lugares, percursos etc. Sua produção, posteriormente analisada pelos pesquisadores, permite a identificação e classificação dos elementos que, segundo a percepção dos respondentes, compõem o ambiente estudado. Embora possibilite uma coleta de dados de grande riqueza informacional, a realização destes trabalhos apresenta alguma dificuldade, sobretudo no que se refere à inibição dos indivíduos frente às tarefas (muitas pessoas sentem-se intimidadas quando solicitadas a se comunicar graficamente) e a decodificação dos dados obtidos.

Saliente-se, ainda, a obtenção e análise de imagens (através do uso de fotografias, filmes ou similares), técnica que pode estar associada a outros métodos (como observação e levantamentos) ou ser considerada isoladamente. Corroborando o conhecimento popular de que “... uma imagem fala mais que mil palavras", as imagens mostram-se essenciais à perfeita compreensão do espaço, considerando o papel fundamental das referências visuais para a percepção e interpretação do ambiente físico (Sanoff, 1991). No entanto, a produção de imagens está intimamente relacionada com a sensibilidade, os recursos técnicos e as oportunidades do fotógrafo/cineasta/etc, encontrando como dificuldade adicional necessitar que os indivíduos a serem documentados aprovem/autorizem a sua realização. Por outro lado, além de simples documentação visual, tal abordagem pode ser associada à coleta de informação junto ao usuário, demonstrando ser um excelente eliciador de conteúdos dificilmente manifestos através de outras formas de coleta (Collier, 1975; Milgran, 1970). O uso de imagens utilizadas como estímulo à análise crítica de um ambiente pelos seus usuários mostrase fundamental à apreensão e discussão do espaço, permitindo, inclusive, o afloramento de elementos de análise não previstos inicialmente na pesquisa.

Quanto ao método de entrevistas verifica-se que, nas formas "livre" ou "semi-estruturada", esta permite o surgimento de dados qualitativamente importantes, essenciais ao desenvolvimento de qualquer pesquisa. Por outro lado, as entrevistas "estruturadas" (nas quais as questões são fixas e direcionadas) possibilitam grande aprofundamento de informações específicas e considerável redução 
no tempo de realização, além de diminuir a dispersão das informações obtidas. A adequada dosagem entre estas formas de coleta (estruturando o processo sem, no entanto, evitar o surgimento de interferências espontâneas do entrevistado), além de ampliar o conteúdo da avaliação e aprimorar o processo, permite o afloramento de elementos antes não cogitados pelo pesquisador. Para a utilização do método de entrevistas é imprescindível treino anterior da equipe e definição precisa dos objetivos e forma de abordagem dos entrevistados, a fim de serem mantidas condições de confrontação e complementação entre os depoimentos obtidos, bem como de se deixarem abertos caminhos para possíveis retornos.

O questionário, bastante conhecido pela população em geral, mostra-se um método rápida e facilmente compreendido pelo respondente, sobretudo quando são aplicadas questões fechadas, redigidas utilizando vocabulário acessível, o mais próximo possível da linguagem coloquial. A tabulação e interpretação das informações mostra-se direta e eficiente, gerando dados essenciais para a realização da análise. Apesar disso a confecção do instrumento geralmente é trabalhosa e lenta, exigindo uma fase de pré-testagem, e para sua aplicação tornam-se necessários tempo e disposição do morador, o que é difícil de estimar antecipadamente.

A livre associação de atributos (Moles, 1970; Ekambi-Schimidt, 1974), por sua vez, constitui-se numa técnica derivada do questionário ou da entrevista (dependendo da forma de aplicação), que exige a participação intensa, porém discreta, do mediador e a busca/captura de associações espontâneas entre o objeto estudado e suas qualidades. Também neste caso verifica-se a vantagem de fácil visualização de elementos ligados à percepção ambiental, sendo que a conceituação e definição gráfica das chamadas distâncias psicológicas (aliando qualidades a objetos concretos) utiliza uma linguagem não-verbal facilmente decodificável, consolidando-se como uma maneira de facilitar o acesso de profissionais ligados ao design às informações de caráter subjetivo.

Enquanto método de pesquisa as medições das condições fisicas do ambiente podem envolver inúmeras técnicas, assumindo a forma 
de medida de dimensões, temperatura, ruído e congêneres; vistorias técnicas ligadas a materiais e processos construtivos; descrição e mensuração de fluxos internos ou externos aos prédios (de pessoas, materiais, veículos etc); levantamento de mobiliário e reformas, entre outros. As medições introduzem grande número de fatores físicos na equação até agora apresentada, dados que podem ser cruzados com a percepção/satisfação dos usuários, possibilitando desde o estudo e checagem de parâmetros e normas construtivas até a discussão de padrões comportamentais face às características de um ambiente. Embora de início tais levantamentos possam parecer interessar mais especificamente aos profissionais ligados à construção civil (arquitetos, engenheiros, e outros especialistas em sua verificação), tornam-se essenciais ao completo conhecimento da realidade, podendo explicar muitos aspectos do comportamento humano, sobretudo a partir da busca da correlação entre os dados obtidos e informações geradas por outros meios.

Resumindo, se isolados os métodos e técnicas anteriormente citados mostram-se capazes de gerar resultados de grande interesse e significado para a discussão da relação pessoa-ambiente, é enorme o manancial de informações gerado pelo cruzamento das informações obtidas através de vários deles, o que justifica plenamente uma maior aproximação cada vez maior entre as áreas de conhecimento que os geraram e alimentam.

\section{Conclusão: uma questão de continuidade}

- Que parâmetros deveriam estar envolvidos na definição de áreas mínimas para uma habitação humana e ecologicamente adequada?

- Como as condições de conforto no ambiente construído (temperatura, ruído, iluminação etc.) alteram o comportamento humano?

- Como o espaço influencia o comportamento de multidões? Existem espaços que se adequem melhor que outros à acomodá-las?

- De que maneira a vida em cidades afeta o comportamento humano? 
- Quais as consequiências da superdensidade? Como trabalhar isso em face da resolução de problemas urbanos?

- Como um sem-teto estabelece sua territorialidade e organiza seu espaço vivencial? Qual a forma de rebater tais informações no projeto de um local que o abrigue?

-Ambientes extremos (como bases espaciais, estações polares, desertos, ilhas isoladas) alteram as condições de convívio entre as pessoas? Como este conhecimento pode auxiliar a repensar / reestruturar tais espaços?

- Que informações são necessárias para o projeto de uma "simples" residência, física e psicológicamente adequada à família que vai habitá-la? Como coletar tais dados de modo a apreender os aspectos vivenciais da relação entre seus membros? Existe um "desenho" que reinterprete tais informações, respondendo às necessidades das pessoas envolvidas?

Questões como estas, típicas de trabalhos em Psicologia Ambiental, são extremamente complexas, apontando tarefas em cuja realização o cruzamento metodológico é essencial, e que necessariamente devem ser abordadas de modo interdisciplinar. Assim, o estudo do comportamento humano no ambiente construído, embora objeto desta área de conhecimento, envolve em sua discussão não apenas aspectos ligados à Psicologia e à Arquitetura, mas exige a participação ativa de várias outras disciplinas interessadas em pensar a qualidade de vida humana a partir da percepção e das vivências dos diferentes agentes envolvidos em cada problemática.

No processo de apropriar-se da realidade para a geração de conhecimento, no entanto, é fundamental que o pesquisador conscientizese do fato de estar, além de buscando informações, também participando de um processo de troca, e interferindo, em maior ou menor escala, na estabilidade (real ou imaginária, duradoura ou efêmera) existente. Insere-se, finalmente, mais um elemento nesta equação (embora isto não signifique relegar tal fator a último plano): a responsabilidade social daqueles que se dispõem a trabalhar a relação pessoaambiente. Tal tarefa se impõe uma vez que, possibilitando o aguça- 
mento do senso crítico do usuário com relação ao local onde vive e à qualidade de vida almejada/obtida, estamos participando ativamente do processo de modificação dessa mesma realidade. Este é mais um assunto a ser discutido... interdisciplinarmente.

\section{Referências}

Barker, R. G. (1968). Ecological Psychology. Stanford, California: Stanford University Press.

Bechtel, R. (1996). The paradigm of Environmental Psychology. American Psychologist, 51, 1187-1188.

Bechtel, M., Marans, R., \& Michelson, E. (Orgs.). (1987). Methods in environmental and behavioral research. New York: Van Nostrand Reinhold.

Collier, J. (1975). Antropologia visual. São Paulo: EPU/EDUSP.

Cullen, G. (1974). El paysage urbano. Barcelona: Gustavo Gilli.

Ekambi-Schimidt, J. (1974). La percepción del habitat. Barcelona: Gustavo Gilli.

Hall, E. T. (1977). A dimensão oculta. Rio de Janeiro: Francisco Alves. (originalmente publicado em 1966)

Ittelson, W. H., Proshansky, H., Rivlin, L., \& Winkel, G. (1974). An introduction to Environmental Psychology. New York: Holt, Rinehart and Winston.

Lynch, K. (1970). La imagen de la ciudad. Barcelona: Gustavo Gilli.

Marans, R. W., Spreckelmeyer, K. F. (1987). Evaluating built environments. Ann Harbor, Michigan: The University of Michigan.

Milgran, S. (1970, março 13). The experience of living in cities. Science, 167, 1461-1468.

Moles, A. (1970). Sociodinâmica da cultura. Barcelona: Gustavo Gilli.

Monzéglio, E. (1990, maio). Uma avaliação perceptiva de habitats da periferia de São Paulo: o pós uso segundo o desenho. Sinopses, n. 13, $26-42$.

Ornstein, S. W. (com Roméro, M.) (1992). Avaliação pós ocupação do ambiente construído. São Paulo: Studio Nobel / EDUSP.

Ornstein, S. W. (1997). Postoccupancy evaluation performed in elementary and high schools of Great São Paulo, Brazil: the occupants and the quality of the school environment. Environment and Behavior, 29 (2), 236-263.

Pinheiro, J. Q. (1986). Os princípios da Psicologia Ecológica como orientadores da avaliação social de edificações: o caso de um centro de convivência. Dissertação de Mestrado não publicada, Instituto de Psicologia, Universidade de São Paulo, São Paulo. 
Preiser, W. F., Rabinowitz, H. Z., \& White, E. T. (1988). Postoccupancy evaluation. New York: Van Nostrand Reinhold.

Proshansky, H., Ittelson, W. H., \& Rivlin, L. (Orgs.). (1970). Environmental Psychology: man and his physical setting. New York: Holt, Rinehart and Winston.

Reis, A. T., \& Lay, M. C. (1995). As técnicas de APO como instrumento de análise ergonômica do ambiente construído. Curso ministrado no III Encontro Nacional / I Encontro Latino Americano do Ambiente Construido (ANTAC), Gramado, Rio Grande do Sul.

Sanoff, H. (1991). Visual research methods in design. New York: Van Nostrand Reinhold.

Sommer, R., \& Sommer, B. (1980). A practical guide to behavioral research, tools and techniques. New York: Oxford.

Stokols, D. (1996). Bridging the theoretical and applied facets of Environmental Psychology. American Psychologist, 51, 11881189.

Gleice Azambuja Elali é $\mathrm{Ar}$ quiteta, Psicóloga, Mestre em Estruturas Espaciais Urbanas (FAUUSP), e Doutoranda na FAU-USP. Professora do Curso de Arquitetura da UFRN e integrante da Base de Pesquisa "Grupo de Estudos Pessoa-Ambientel GEPA". Correspondência: Av. Getúlio Vargas, 782, ap. 1101 - Petrópolis, Natal, RN (59.010-360). Tel/fax: (084) 202.4270 - 202.4433. E-mail: mgelali@truenetrn.com.br
Sobre o autor 